\title{
Biological aspects of the genus Myricaria Desv. (Tamaricaceae), especially of the Siberian species
}

\author{
Elena Lyakh* $^{*}$ \\ Central Siberian Botanical Garden SB RAS, Novosibirsk, Russia
}

\begin{abstract}
Observations of the shrub Myricaria (Tamaricaceae) in the wild during expeditions and at the Central Siberian Botanical Garden SB RAS (Novosibirsk) has elucidate their taxonomy, and revealed that rather than four taxa, just two are present in Siberia. Without this understanding of the phenology, the systematics of the species was much confused. The two species of Myricaria (M. bracteata Royle, M. longifolia (Willd) Ehrenb.) in Siberia a are valuable plants for marginal land, urban landscaping and erosion control on river banks. Plants of the genus Myricaria are the traditional Tibet medicinal plants. At present, as a result of geological explorative and road-building works, the natural habitats of Myricaria are destroy. The features of blossoming and fructification of Myricaria Siberian species of in nature and in cultivation were studied and described for concervation of these valuable plants at the botanical gardens. As a result of the experiments, the temperature features of germination and preservation of seeds was developed.
\end{abstract}

\section{Introduction}

The genus Myricaria Desv. is represented by species distributed in Asia (the Himalayas, southern China, Siberia, and Central Asia) and in Europe (Mediterranean area and Scandinavia). At present time there are about 13 species: Asia, Europe; ten species (four endemic) in China [1].

Two species of Myricaria are found in Siberia: Myricaria bracteata and M. longifolia. They are abundant on short-lived sandbars, gravel banks and other alluvial deposits of the rivers of southern Siberia (Altai, Tuva, West and East Sayan, Buryatia, ets.) [2]. Both species of Myricaria are bushes up to $2 \mathrm{~m}$ in height. The bark of new growth is initially yellowish-green in colour, and become brownish-gray on older stems. The stems bear numerous, densely packed second and third order branches. The leaves are glaucous-green. Their systematic history and morphological variability in Siberia has been reviewed in a publication [3].

Moreover, their deep highly developed roots system makes them excellent for erosion control of vulnerable sites, especially river banks. In addition to the decorative and

\footnotetext{
*Corresponding author: 1 lyakh@,rambler.ru
} 
functional qualities, they are the medicinal plants, honey source, used as fodder and, and produce tannins and flavonoids which have been exploited in the region [4, 5].

At the Central Siberian Botanical Garden extensive cultivation and propagation trials have been undertaken in parallel with a review of the ecology and morphological variability of two species.

\section{Materials and methods}

Observations on the flowering and fruiting of both species was conducted at the introduction nursery of the Central Siberian Botanical Garden, as well as in the wild during expeditions to the Altai, Western and Eastern Sayan. Seeds of Myricaria were collected both in the nursery and from wild populations during these expeditions. The research was focused on understanding the conditions under which germination takes place in the natural state; the optimal conditions for germination under controlled laboratory conditions (temperature, humidity, etc.); and recording germinability levels of fresh seed, and seed collected and stored under a number of different conditions

Seed storage and germination requirements were investigated for the purpose of drawing up protocols.

The germinability of M. bracteata was investigated by sowing 100 seeds on wet filter paper in a Petri dish. For each treatment, 4 replicates were made. Germination trials were conducted on wet filter paper in Petri dishes in 4 cups- $\mathrm{x}$ reconsideration of 100 seeds. The seeds are stored at room temperature $\left(20^{\circ} \mathrm{C}\right)$ and at a temperature of $5^{\circ} \mathrm{C}$ in the refrigerator. We studied the productivity of fruit and seed by the special technique of introduced species $[6]$.

\section{Results and discussion}

The fruit is elongated, pyramidal or pear-shape splits septicidally, and the carpels usually number 3 (2-5). The seeds are small (to $1 \mathrm{~mm}$ in length) and bear an apical awn, which has numerous branches in its upper half, allowing the seed to be readily transported by wind. The embryo is large, and straight, and endosperm is absent in the ripe seeds [7].

Earliest signs of germination usually occurs within 8-10 hours of sowing. After 24 hours the seedlings have firmly attached to the substratum, and the cotyledons appear. After 3-4 days, there is a period of intensive root growth, and than this the stem produces the first true leaves on about the $10^{\text {th }}$ day. Under natural situation Myricaria seedlings germinate on the sandy and pebbly deposits of river beds where suitable levels of groundwater and surface sediments occur. The seedling are very small, and mist help to dry out. During the first two weeks in particular, the seedlings should be kept almost excessively wet. Usually it is only possible to maintain this with sowings in greenhouses or under plastic film with regular irrigation. However, at the same time this raises the risk of death from excessive heat. Over the course of the first 6 to 8 weeks, until the roots are sufficiently developed, seedlings remain especially sensitive to drought.

After the first growing season, seedlings reach a height of ca. $10-15 \mathrm{~cm}$ with $3-5$ stems, and possess a well-developed root system. By the end of the second growing season the plants will be $40-45 \mathrm{~cm}$ in height, with 7-12 stem. By the third year, growth becomes more rapid, and during May-June, the number of shoots increases to ca. 20, with individual shoots reaching $80 \mathrm{~cm}$ in length. Plants grown from seed begin flowering by their $4^{\text {th }}$ year.

In cultivation and in the wild, the shrubs bloom for an extended period of 50-60 days. There are two terms of blossoming and two types of inflorescences: lateral and apical. Lateral inflorescences arise from one-year old wood, while apical inflorescences are borne 
on the tips of new shoots. The lateral inflorescences begin blooming from the beginning of June to the beginning of July (Fig. A, B), whilst the terminal inflorescences bloom from mid-July to the beginning of August (Fig. C, D).
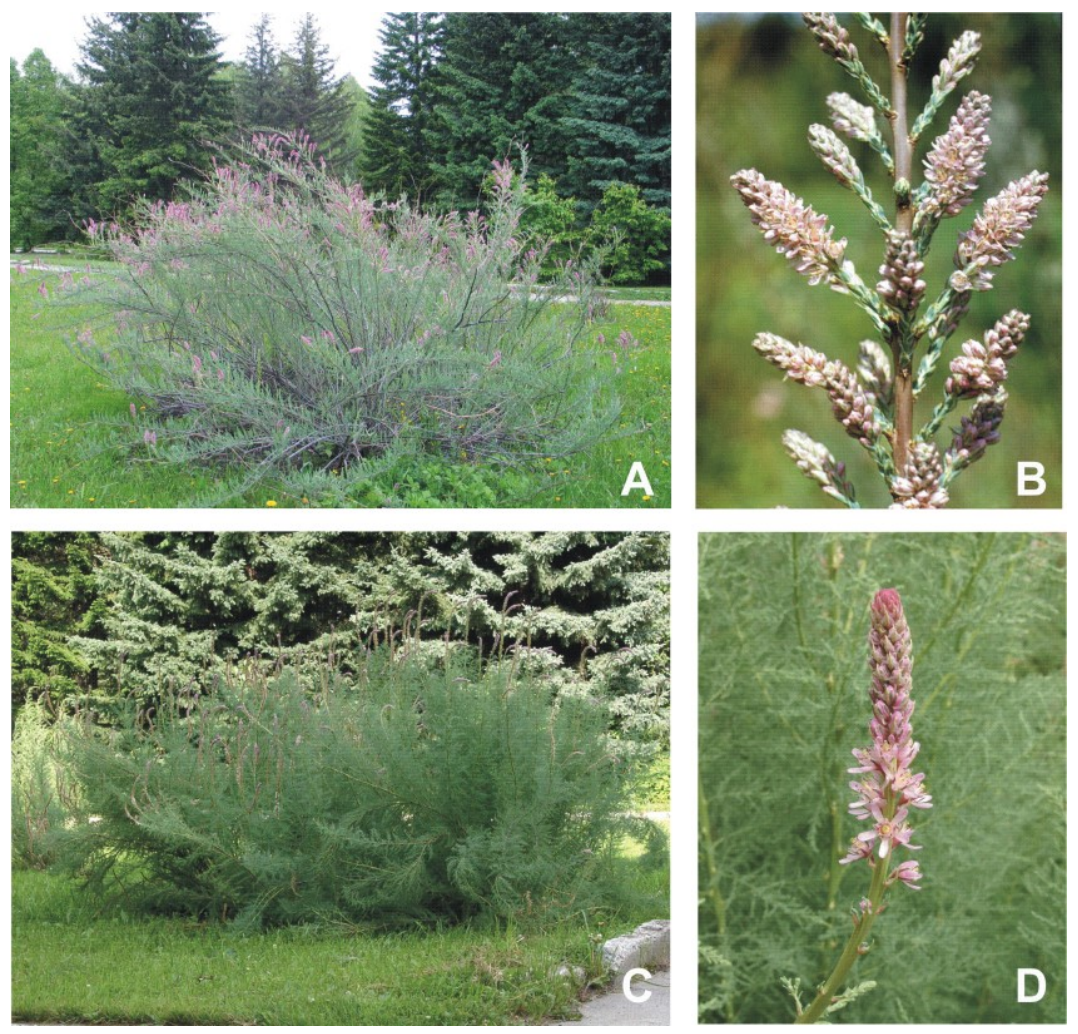

Fig. A - blooming of lateral shoots of Myricaria bracteata; B - lateral shoots; C - blooming of terminal shoots of Myricaria bracteata; D - terminal shoot.

Observations on M.bracteata in culture showed that the lateral flower buds, developed in the previous autumn, from late May to early June, open simultaneously with the opening of new leaves. A single stem bears from 35 to 40 inflorescences, up to a maximum of 60 . Mass flowering occurs over a period of ca. 10-20 days. The individual flowers last live about 3 days, following which they fade quickly, and the fruit develops. Developing basipetally, each inflorescence blooms over a period of ca.15-17 days, and extends during this period some 3 to 4 times its original length.

Seed set in high, and the seeds ripen quickly, some 5-6 days after the flower has faded. Individual fruit capsules mature within 14-18 days of the flower fading, they discover how and seeds moving by wind.

Both species are characterized by high fruit and seed productivity, and showed comparable results. Fruit production was compared in natural stands, and amongst cultivated plants at the Central Siberian Botanical Garden.

A wild population of $M$. longifolia was examined in Buryatia, in the Tunkinskaya Valley of the Irkut river. Each lateral inflorescence produced from 15 to 18 fruits, which represenrs $66,5 \%$ of the total number of flowers. Non viable seeds determined visually represent approximately $25-30 \%$. Thus a single fruit contains a total of $77-85$ viable seed out of a total of 110-120. The figures for plants grown in culture are considerably higher, up to $95 \%$. There is a slight difference in the productivity of stems of first order and second 
order shoots, which are respectively $60 \%$ and $76 \%$. In cultivation such differences did not occur, with the same order of branches giving figure of $94 \%$ and $96 \%$ respectively.

As the lateral inflorescences finish flowering, herbaceous shoots of the present seasons growth develop apical inflorescences, and these new flower buds are developed, at the Central Siberian Botanical Garden by June 10-18. These shoots are erect, and are typically some $95-120 \mathrm{~cm}$ in length. The apical inflorescences typically begin flowering 20-24 June, When the first flowers emerge the inflorescence branches are some 6-9 cm long, lengthen 4-5 times during the course of flowering to some 35-40 in length. The whole compound inflorescence lasts 17-30 days. During this period the central axis may become twisted and may incline downwards. Because new inflorescences are developing and opening all the time, the shrub can be in flower until August 12 to 16 (in the Botanical Garden). New herbaceous shoots develop from May onwards, but this becomes particularly marked after flowering. From the beginning of August to September new flower and leaf buds, that will from the lateral inflorescences and leaves for next year, are developed.

There are no essential differences in flowering behaviour between M. bracteata and $M$. longifolia. M. longifolia lateral inflorescences begin blooming from late May to early June, again simultaneous with leaf emergence, and this lasts until mid-June. The apical inflorescences of this latter species have a tendency to be somewhat larger and more complex and less compact.

Valery N. Nekrasov divides the seeds of woody plants according storage into three groups. The seeds of Myricaria belong to the first group: they rapidly lose germinability after separation from the maternal plant and require special storage regimes (Nekrasov, 1973) [8]. Two regimes were investigated: storage under room conditions at $20^{\circ} \mathrm{C}$, and refrigerated storage at $5^{\circ} \mathrm{C}$. These temperatures were selected as they reflect the June temperature regimes of the native mountainous habitats.

Longer-term storage was studied for M. bracteata (collected in the Altai Mountains) and $M$. longifolia (collected in Tuva). Seeds stored at room temperature $\left(18-20^{\circ} \mathrm{C}\right)$ for a month showed complete loss of germinability under the protocols used. Seed stored at a temperature of $3-5^{\circ} \mathrm{C}$ demonstrated a rapid loss of germinability, to $17-20 \%$ after one year. Measurements were undertaken after 1, 2, 6 and 12 month intervals following sowing.

In laboratory conditions, at a temperature of $18-20^{\circ} \mathrm{C}$, seeds begin to germinate after 46 hours. Seeds, sown on the day of collection, showed germination rates of $27-29 \%$ after 8 days. Additional experiments on temperature variation were undertaken for M. bracteata. Three parallel regimes were established; firstly seed germinated at room temperature of $20^{\circ}$ $\mathrm{C}$; secondly seeds germinated at $30^{\circ} \mathrm{C}$; and thirdly seed exposed to $30^{\circ} \mathrm{C}$ for the 48 hours, and the subsequent days at room temperature of $20^{\circ} \mathrm{C} /$ The initial high temperature led to a marked increase in germination rates.

Storage for one night at $5^{\circ} \mathrm{C}$, however, resulted in a germination rate of $92-96 \%$ after 4 days. Further periods of storage at $5^{\circ} \mathrm{C}$ for periods from 2 to 5 days, gave similar rates of 93-95\%.

\section{Conclusions}

Siberian species of Myricaria have two distinct flowering episodes separated by only a few weeks, giving a flowering season up to two months. There are two terms of blossoming and two types of inflorescences: lateral and apical. Without this understanding of the phenology, the systematics of the species was much confused.

Myricaria have been shown to have a short viability, and although a large number of seeds are produced each year, the seeds must germinate quickly, preferably after a very short cold period. In the natural conditions of gravel river beds, the cold water constant wetness allow rapid germination to occur. Warm day temperatures also seem to be 
important for seedling establishment. As a result of geological explorative and roadbuilding works, the natural habitats of Myricaria are destroy. One of possible ways of propagation of Myricaria species is that by seeds.

Seed storage and germination requirements were investigated for the purpose of drawing up protocols. As a result of the experiments, the temperature regime of germination and preservation of seeds was developed.

Seeds have a short germinability, and those of both species should be stored at about $5^{\circ}$ C. Germination rates for fresh, viable seeds is $90 \%$, and declines to $20 \%$ after 12 months storage at $5^{\circ} \mathrm{C}$. Laboratory germination rates doubled when seeds were subjected to an alternating temperature regime $\left(30^{\circ} \mathrm{C}\right.$ followed by $\left.20^{\circ} \mathrm{C}\right)$.

\section{Acknowledgements}

I would like to thank Dr. Matthew Jebb, Director of the National Botanical Gardens of Ireland for value advices and for assistance in translating this publication.

Work is carried out in frames of the projects of the state mission of the Central Siberian Botanical Garden of SB RAS № AAAA-A17-117012610054-6 with applying of bioresource scientific "Collection of Living Plants in Open and Closed Ground" USU 440534.

\section{References}

1. Z.Y. Wu, P.H. Raven, D.Y. Hong, (eds.), Flora of China, 13 (Beijing, 2007)

2. G.A. Peschkova (ed.), Flora of Siberia, 10 (Science Publishers, Enfield, NH, USA, 2006)

3. E.M. Lyakh, Eurasian Journal of Forest Research, 16 (2013)

4. A.A. Chernonosov, E.A. Karpova, E.M. Lyakh, Revista Brasileira de Farmacognosia, 5 (2017)

5. E.M. Lyakh, N.V. Tsybulya, Plant Resourses, 45, 1 (2009)

6. M.G. Nikolaev, I.V. Lianguzova, L.M. Pozdova, Biology of Seeds (SPb., Nauka, 1999)

7. A.L. Takhtajan, Comparative anatomy of seed, 4 (SPb., Nauka, 1992)

8. V.I. Nekrasov, Basics of Seed Science of Wood Plants in Introduction (Moscow, Nauka, 1973) 